\title{
NOTAS PARA LA EDICIÓN CRÍTICA Y ANOTACIÓN DEL POEMA DESCRIPCIÓN DE LAS GRANDEZAS DE LA CIUDAD DE SANTIAGO DE CHILE (1740)
}

\author{
Carlos Mata Induráin \\ Universidad de Navarra \\ cmatain@unav.es
}

\section{RESUMEN / ABSTRACT}

La Descripción de las grandezas de la ciudad de Santiago de Chile, uno de los pocos textos del corpus de la poesía satírico-burlesca del Chile colonial, de autoría discutida, ha contado con algunas ediciones recientes que no resultan del todo satisfactorias, especialmente desde el punto de vista de la fijación textual. Este trabajo quiere poner de relieve las carencias de esas ediciones modernas y, por consiguiente, la necesidad de una edición crítica, hecha con criterios filológicos rigurosos, y completada con una anotación amplia que clarifique los abundantes juegos dialógicos y las agudezas varias que recorren los versos de la Descripción.

Palabras clave: Descripción de las grandezas de la ciudad de Santiago de Chile, poesía satírico-burlesca, literatura colonial chilena, Ignacio Mendieta, edición crítica.

Descripción de las grandezas de la ciudad de Santiago de Chile is one of the few texts included in the satirical and comic textual corpus of colonial Chilean poetry. The authorship is still controversial. Recently, some critical editions have been made, although they are not fully acceptable taking into consideration the textual fixation. This paper intends to point out the weaknesses in those modern editions, and consequently the need of a new one. The prospective new edition should follow rigorous philological criteria and a complete annotation to clarify the prolific dialogical games and witticisms present all along the Descripción verses.

KEY WORDS: Descripción de las grandezas de la ciudad de Santiago de Chile, satirical and comic poetry, colonial chilean literature, Ignacio Mendieta, critical edition. 
En el no muy extenso corpus de poesía satírico-burlesca del Chile colonial ${ }^{1}$, el texto al que ahora quiero dedicar atención ocupa un lugar destacado y ofrece, sin duda, un interés muy notable. La Descripción de las grandezas de la ciudad de Santiago de Chile no es una obra desconocida, y de hecho ha contado con algunas ediciones recientes que, aunque no carecen de méritos, no resultan del todo satisfactorias, especialmente desde el punto de vista de la fijación textual. El objetivo de este trabajo no es tanto el análisis del contenido satírico del poema, ni la dilucidación del debatido problema de su autoría; se trata más bien de poner de relieve las carencias de esas ediciones modernas del texto y, por consiguiente, la necesidad de una edición crítica, hecha con criterios filológicos rigurosos, y completada con una anotación amplia que clarifique los abundantes juegos dilógicos y las agudezas varias que recorren los versos de la Descripción. En cualquier caso, antes de entrar en materia, abordaré algunas cuestiones relativas a los testimonios conservados, la autoría, la estructura y el contenido del poema.

\section{CUESTIONES PRELIMINARES: DATOS TEXTUALES, AUTORÍA, ESTRUCTURA Y CONTENIDO}

La Descripción de las grandezas de la ciudad de Santiago de Chile es un poema satírico fechado en 1740 y de autoría discutida que, escrito en forma dialogada, se burla de las supuestas grandezas de la capital chilena (grandezas que, en realidad, no pasan de ser mera pompa, vanidad y apariencia). Presenta la peculiaridad de ofrecer coincidencias textuales muy notables con ciertos versos conservados en los manuscritos poéticos de Juan del Valle y Caviedes que enderezan su sátira contra la ciudad de Lima.

1 Véase Promis, La literatura del Reino de Chile. Embry escribe: "La poesía satírico descriptiva en la tradición colonial chilena, sin la calidad que alcanzó en el XVII y XVIII en otras regiones de Hispanoamérica, y particularmente en Lima, no debe haber sido tampoco una planta exótica" (“Estudio preliminar" 23). Madrigal presenta la pieza como "buen ejemplo del vigor, la importancia y la difusión del género satírico en la América Colonial" (154). 


\subsection{Panorama textual y autoría}

El poema se nos ha transmitido en dos copias manuscritas (Biblioteca Nacional de España y Biblioteca Nacional de Chile) y cuenta con tres ediciones modernas, debidas a Embry (1994), Madrigal (1994) y Promis (2002). Una de las versiones manuscritas se halla en el Ms. 17.667 de la BNE, con tejuelo Varios de Lima y letra del siglo XVIII, que fue descubierto por Rubén Vargas Ugarte y contiene una serie de piezas peruanas de época virreinal $^{2}$. Perteneció a la biblioteca de Pascual de Gayangos y, según suposición de Vargas Ugarte, "parece haber sido coleccionado por el chileno D. Juan Antonio Tristán y Doyangue, del cual se guardan en él algunas composiciones" (Cit. en Madrigal 154). En efecto, la firma de Juan Antonio Tristán aparece al final de todo el manuscrito, en el folio 175v: "Ad maiorem Dei gloriam, santisimeque Deipater, / Virginisque Marie, omnium santorum santarumque. // Joannes Ant.o Tristan libendissime me scripscit"33. La última composición del conjunto (ocupa los folios 152r-176v) es la Descripción de las grandezas de la ciudad de Santiago de Chile, dedicada por el Desengaño a los muy ilustres señores gamonales de ella, escrita este año de $1740^{4}$, y en el folio $175 \mathrm{r}$ se ha añadido al margen derecho, de otra mano: "Don Ignacio Mendieta, / vecino de Santiago de / Chile".

La otra copia manuscrita (que presenta varias divergencias textuales con la conservada en Madrid) se localiza en el Fondo Medina de la Biblioteca Nacional de Chile, testimonio en el que, como escribe Promis,

la firma de Ignacio Mendieta ha sido reemplazada por la frase: "Acabóse. Pasa a la venta". Esta versión difiere de la anterior en que tiene algunas estrofas agregadas, a la vez que adolece [entiéndase: carece] de varias otras contenidas en el manuscrito de la Biblioteca Nacional de Madrid. Además, alguien colocó como fecha el año 1722, lo cual es incorrecto porque en el texto se alude al terremoto de 1730 y se anuncia otro que sucederá en 1740. En general, la copia de Medina

${ }^{2}$ La descripción completa del manuscrito puede verse en Paz 393, núm. 1.348.

${ }^{3} \mathrm{Y}$ en el folio 3v se leía: "Ego D. Joannes Antonius Tristanensis scripsi libentissime Jacobopoli Regni Chilensis. Anno 1742”.

${ }^{4}$ En las ediciones de Embry y Madrigal, que transcriben este manuscrito, el título figura como: Descripción de las grandezas..., dedicadas... En el original conservado en la BNE se escribió, en efecto, dedicadas, pero se aprecia claramente que la $s$ está tachada, y hace así mejor sentido: Descripción..., dedicada a ..., escrita en... 
está en bastantes malas condiciones e incluso ha perdido versos debido a la rotura de algunas páginas (529).

La autoría de esta sátira en verso es controvertida, pues -como ya indiquépresenta una fuerte intertextualidad con versos atribuidos a Valle y Caviedes en los que la ciudad objeto de sátira es Lima: se trata, en concreto, de los poemas "Coloquio entre una vieja y Periquillo a una procesión celebrada en esta ciudad" y "Preguntas que hace la Vieja Curiosidad a su nieto el Desengaño, niño Perico, hijo de la Experiencia, de las grandezas de una ciudad de los Reinos Yermos, Andurriales" (en las ediciones de Reedy y CáceresCisneros-Lohmann Villena), unidos en un solo poema, "Coloquio entre la Vieja y Periquillo sobre una procesión celebrada en Lima”, en la edición de Vargas Ugarte. Por su parte, conviene recordar que García-Abrines no editó estos versos dentro del corpus poético de Caviedes, y así lo explicaba:

El estilo de estos poemas [se refiere tanto al "Coloquio" y las "Preguntas" como a otros que también ha eliminado de su edición] no es el de Valle y Caviedes. Por el momento desconocemos el nombre de sus autores, pero muchos de ellos, si no todos, tienen que ser de los concurrentes a la Academia del virrey, Manuel Oms de Santa Pau, Olim de Senmanat y de Lanuza (En su prólogo a Valle y Caviedes, Obra poética, II, 19).

Según cálculo de Madrigal (157), sobre un total de 1394 versos que forman el cuerpo de la Descripción, 346 coinciden con los de la sátira limeña, atribuidos a Valle y Caviedes. Entonces, ¿la sátira de Lima fue aprovechada y ampliada para aplicarla a Santiago o, más bien al revés, de la sátira de Santiago, más extensa, se desgajaron algunos versos para dirigirlos contra la capital peruana? Lorente cree que el texto original es la Descripción, y que los colectores de la obra poética de Caviedes pusieron esos versos bajo su nombre dado su prestigio como poeta satírico:

Ésta es la historia de la transmisión textual de la Descripción de las grandezas: lo que en el original constituye una sátira a la ciudad de Santiago de Chile en respuesta al "ultraje vano" que hizo "un Dómine Camote / a la Corte (Lima) bella" (fol. 175r), realizada muy probablemente por D. Juan Antonio Tristán, se convierte, previamente deturpada, en dos sátiras contra la ciudad de Lima. Ignoramos cómo tuvo lugar el proceso. Lo que sí podemos asegurar es que los colectores de los diversos manuscritos que contienen la 
obra poética de Caviedes y la recogen, ya han perdido su vinculación directa con el autor, hasta el punto de desconocer su nombre y ofrecer una lectura que por momentos carece de sentido. Si la Descripción fue escrita en Santiago de Chile en 1740 y Tristán pasó a Lima en 1745 como componente del séquito del Conde de Superunda, debió de transcurrir mucho tiempo para que se olvidara la paternidad de su autor, se aprovechase fragmentariamente en la composición del "Coloquio" y de las "Preguntas", se perdiese la conciencia de su título primitivo y se atribuyese a Caviedes. El tiempo suficiente como para avanzar la fechación de los Mss. A, B, C, D y E, al menos en su versión definitiva, a la segunda mitad del siglo XVIII, y más exactamente a su último tercio 5 .

Otros estudiosos, en cambio, opinan de modo contrario. Fue Madrigal quien primero llamó la atención sobre la supuesta deuda de la Descripción con Valle y Caviedes, al describir así la obra:

Se trata de un[a] descripción satírica de la capital de Chile y del país mismo en la primera mitad del siglo XVIII, escrita en romance y que, dentro de la historia de la poesía satírica en el Chile colonial, no era conocida. Tal falta de notoriedad quizás explique el que, hasta donde se me alcanza, nadie haya reparado en que esa descripción de Santiago de Chile reproduce, en parte apreciable, versos de Juan del Valle y Caviedes dedicados a Lima (154).

En el apartado de su estudio titulado "Caviedes y la Descripción" analiza las deudas con el poema o poemas de Caviedes; y en otro, "Lo original en la Descripción", añade el dato que antes mencionaba: "de los 1394 octosílabos que lo forman [el cuerpo del poema], 948 no constan en Caviedes; esto es, el $68 \%$ de los versos de esa parte principal son, aparentemente, originales" (157). Concluye indicando:

A pesar de la deuda con Caviedes, la Descripción es, en gran medida, original. Muestra un cierto conocimiento, no sólo de la obra del peruano, sino del género satírico en general y de sus motivos predilectos, y logra una visión vívida, burlona y acre, de Santiago de Chile alrededor de 1740 (162).

5 Véase Lorente 1083-1084 (cita en 1084). Para Madrigal, lo de "Dómine Camote" sería una alusión a Caviedes; véase Madrigal (158) y Lasarte, "La Vieja y el Periquillo" 126. 
Promis, por su parte, se hace eco de esa opinión acerca de la dependencia con respecto a los versos limeños:

El texto escrito por Ignacio Mendieta -en caso de ser efectivamente el autor del poema- no es enteramente original. La Descripción de las grandezas... se genera a partir de dos poemas que compuso Juan del Valle Caviedes, el gran escritor satírico peruano de la época virreinal, para censurar y mofarse de las costumbres de la sociedad limeña de su tiempo. El autor de la Descripción ha unido los dos poemas de Caviedes modificando algunos de sus versos para que apunten al nuevo objeto de la sátira, la ciudad de Santiago, y ha agregado una considerable cantidad de versos y estrofas para "chilenizar" el texto original del poeta limeño. Todos estos cambios y adiciones dan como resultado que aproximadamente el setenta por ciento de la Descripción es original de Ignacio Mendieta, o del anónimo admirador de Caviedes que decidió utilizar sus poemas como punto de partida para desarrollar una sátira mordaz, desenfadada $\mathrm{e}$ irreverente de los chilenos y de sus costumbres en la primera mitad del siglo XVIII (529).

En fin, Lasarte va incluso más allá, y no solo defiende la autoría de Valle y Caviedes para los versos compartidos por las sátiras santiaguina y limeña, sino que conjetura -apoyándose en lo expresado por Madrigal (157)- que todos los versos de la Descripción podrían ser suyos:

Este tipo de préstamo que lleva a cabo la Descripción, como bien se sabe, no era nada fuera de lo común. Si es así, ¿por qué no pensar entonces que toda, o casi toda, la obra perteneciese inicialmente a la pluma de Valle y Caviedes? ${ }^{6}$

¿Quién pudo ser, entonces, el autor del texto de la Descripción? Lo más sensato parece afirmar, como hace Embry, que "Sobre la identidad del autor aún no hay certeza" ("Estudio preliminar" 9), idea que desarrolla en otro lugar:

6 Véase Lasarte, “La Vieja y el Periquillo" 126-127 (cita en 126); para la sátira limeña, Lasarte, Lima satirizada 112-118 y 180-192; y un contexto más amplio sobre la sátira peruana en Lasarte, Mateo Rosas de Oquendo. 
No se ha podido dar aún con la identificación del autor de este poema satírico de Santiago. No cabe duda que su autor fue un peninsular avecindado en la ciudad de Santiago, probablemente algún oficial menor de la administración desencantado por los sucesos políticodiplomáticos suscitados entre Lima y Santiago durante el conflicto de la comercialización del trigo, al ver la reacción de la capitanía general, encabezada por el gobernador y el cabildo, ante la intervención del virreinato que intentaba fijar el precio al trigo chileno, dominar el sistema del circulante al suspender el pago de sus compras en moneda metálica para obligar el retorno de mercancías peruanas; combate al contrabando y, sobre todo, la intervención del consulado de Lima en conflictos comerciales en jurisdicción chilena. La forma anónima del manuscrito se intentó romper en el mismo siglo XVIII, cuando una segunda mano, en el margen derecho y al final del texto propiamente tal, inscribió el nombre de "Ygnacio de Mendieta / Vecino de Santiago" ("Santiago de Chile" 32, nota 5).

En efecto, está documentada la existencia de Ignacio Mendieta, natural de Guernica, que pasó a Chile en 1691 y murió poco después de mayo de 1743. Aunque no llegó a conocer el texto de la Descripción, José Toribio Medina, ya en 1878, hacía referencia en su Historia de la literatura colonial de Chile a la obra y mencionaba el nombre de Mendieta como su posible autor: "Pérez García cita un poema descriptivo de la ciudad de Santiago que redactara un tal Mendieta, y del cual no se tiene noticia" (Cit. en Embry, "Santiago de Chile" 32, nota 4). Por su parte, Pedro Roca, en su Catálogo de manuscritos que pertenecieron a D. Pascual de Gayangos existentes hoy en la Biblioteca Nacional, pone el nombre de Ignacio Mendieta entre interrogantes. Otro nombre que también se ha señalado es el de José Mendieta ${ }^{7}$, hijo del anterior (hipótesis apuntada por Pérez García). En fin, el autor pudo ser Juan Antonio Tristán, el responsable de la recopilación conservada en la Biblioteca Nacional de España (BNE) y autor también de un Poema Scotida en honor de Duns Scoto, incluido en ese mismo manuscrito.

En suma, la autoría de la Descripción de las grandezas de la ciudad de Santiago de Chile es cuestión que resulta controvertida y se entrecruza

7 Pueden verse más datos sobre los Mendieta en Embry, "Estudio preliminar" 10, nota 7 y "Santiago de Chile" 32-33, nota 5. En estos dos trabajos de 1994, Embry reelabora uno anterior de 1991-1992. 
además con complejos problemas textuales relacionados con la transmisión de las obras poéticas de Valle y Caviedes.

\subsection{ESTRUCTURA EXTERNA}

Desde el punto de vista externo, la obra consta de las siguientes secciones:

1) Un soneto "Dedicatoria" a los ilustres señores gamonales 8 (los criollos principales) de la ciudad de Santiago. En ella el autor recurre al tópico de la falsa modestia ("toscos palotes de impericias mías", "de mi musa las tibiezas", "mis boberías"); pero, al mismo tiempo, asegura que sus versos vivirán "siglos inmortales" en virtud del "prelevado asunto" que tratan, y por el hecho de estar dedicados a ellos, a los gamonales santiaguinos, que "en aplausos tan universales / eternizasteis vuestras fantasías". Apunta ya aquí la clave de la sátira nuclear en todo el poema: la imagen de "grandeza" que tales patricios y jefes tienen de la ciudad $y$, en general, de todo el país responde solo a vanas "fantasías" suyas, es decir, se plantea el conflicto básico entre la realidad y la apariencia.

2) Cuatro quintillas con la "Censura de la Suprema Experiencia" (no de la Suprema Inquisición), en las que se insiste en la mala calidad del poema y en su carácter de obra primeriza (el autor, se dice ahí, no debiera "escribir tan confuso, / tan tosco y desaliñado", "con musa tan friona", y aunque se ve claro que su ofrenda "es grande frionera", se admite "por ser primera").

3) El cuerpo del poema (1394 versos de romance con rima $e$ a), bajo el título "Preguntas que, impelida de la vocinglera Fama, hace la anciana Curiosidad a su nieto el Desengaño, hijo de [la] Experiencia, quien con verídico informe intenta desvanecer el común error que por la siniestra relación de sus patricios han consebido los estraños". Los veinte primeros versos sirven como introducción de los personajes, y el resto es el diálogo entre ambos locutores, Vieja y Perico.

4) Indicación de "Fin" y a esa altura (fol. 175r), en el margen derecho, un añadido de otra mano: "Don Ignacio Mendieta, / vecino de Santiago de / Chile".

${ }^{8}$ Para esta palabra, véase Lohmann Villena, "Gamonal”. 
5) Cinco cuartetas finales, numeradas en arábigos, donde se explicita que "Este bien formado diálogo, / que consta de la experiencia, / lo escribió con gran acuerdo / de Europa un insigne poeta / al ver el ultraje vano, / de Santiago en competencia, / que hizo un dómine Camote / a la Corte (Lima) bella". Y ello "para que con la noticia / la gran peruana cabeza / castigue el atrevimiento / de la soberbia chilena".

6) El ya mencionado explicit final, en el que la indicación "Joannes Ant.o Tristan libendissime me scripscit” ('Juan Antonio Tristán me escribió / me copió con muchísimo gusto') parece referirse no al poema, sino al conjunto del manuscrito.

\subsection{CONTENIDO E INTENCIONALIDAD DE LA SÁTIRA}

El objetivo principal del poema es satirizar la idealizada imagen que de Santiago (y, en general, de Chile) tienen sus gentes principales. En realidad, las supuestas grandezas no son más que pura apariencia. De ahí la abundancia del léxico relacionado con este campo de lo vano y fantasioso: fantasías, quimeras, patrañas, novelas, faramalla, oropeles exteriores, máquinas opulentas, vanos faustos, pompas, humo, etc., que pone de manifiesto el conflicto entre la pura apariencia (para los gamonales, Santiago es Cairo suprema, Babilonia nueva, confusa Babel, fabulosa Creta, imaginada Menfis, fantástica Atenas...) y la verdadera realidad (la ciudad es más cortijo que Corte): "Todo paja, ningún grano, [...] / mucho ruido, pocas nueces" (vv. 1331-1333).

Algunos motivos satirizados (coincidentes con los versos de la sátira contra Lima) son: los caballeros chirles, con su ridícula ostentación de nobleza, su afán de hidalguía, su abuso del don ("muchos dones, pocas rentas", v. 1334), etc.; o el afán por estar a la moda, el lujo exagerado, tanto en los varones como en las mujeres. Todos estos son motivos bien conocidos en la tradición española. Pero más interesantes me parecen los motivos satíricos relacionados específicamente con la situación chilena ${ }^{9}$, a saber:

${ }^{9}$ Cabe destacar la mención de topónimos y otros nombres que subrayan el carácter chileno del texto: Valdivia, Colchagua, Renca, Recoleta, Mapocho, Ramón y Vitacora, Chimbarongo..., al igual que la alusión a determinadas circunstancias y hechos históricos, específicamente de Chile, no de Perú. 
a) la pereza de los chilenos; la tierra del país es muy fértil, pero queda improductiva por la "flojera" (v. 174) y la falta de ambición de sus gentes:
Porque es ya constitución
en esta gente grosera
que, en teniendo doce vacas,
más caudal ya no desean;
y cansados del trabajo,
alegres con tal riqueza,
se emplean en hacer hijos
y dormir a pierna suelta (vv. 185-192);

b) los problemas por la falta de agua potable: se alude a la insalubridad del río Mapocho y a la incapacidad para la canalización de las aguas (existen buenos manantiales en Ramón ${ }^{10}$ y Vitacora=Vitacura, pero la indolencia generalizada hace que no se aprovechen);

c) la decadencia militar, ejemplificada en la incapacidad de defensa frente a los ingleses, con los que se estaba en guerra en ese año de 1740 (se hace referencia al ataque de una escuadrilla enemiga a Valdivia y la tardía llegada de los refuerzos enviados ${ }^{11}$, al tiempo que se pone de manifiesto la cobardía de los soldados y el mal estado de las defensas);

d) el desprecio por los asuntos sagrados, la dejadez en el culto divino: en una procesión, a falta de una imagen de Santa Isabel, sacan la del patrón Santiago con la barriga del embarazo hecha de trapos (es decir, queda una santa "con barbas en las mejillas / y patas, a la chilena", vv. 487488); un San Sebastián está vestido "a la francesa" (v. 908); en el paso de la Cena, ponen a los doce Apóstoles con poncho "porque chilenos parescan" (v. 930); se hacen entierros hiperbólicamente suntuosos, etc.

Frente a otras exageradas descripciones panegíricas (por ejemplo, las expresadas por los cronistas y las contenidas en las descripciones serias del país), el autor nos ofrece una visión satírica, degradada: las supuestas

${ }^{10}$ Madrigal aporta una muy documentada nota al respecto: se refiere al estero de Rabón, topónimo indígena deformado en Ramón (Madrigal 202).

${ }^{11}$ La circunstancia del hecho histórico y el tono satírico del pasaje recuerdan los del soneto de Cervantes "A la entrada del Duque de Medina en Cádiz" (véase Mata Induráin, "El soneto de Cervantes"). 
grandezas -ya lo he indicado-no son más que pura apariencia. Como escribe Embry:

Resulta evidente que la intencionalidad de este poema descriptivo es minimizar la imagen general de grandeza que había alcanzado la ciudad de Santiago de Chile en las primeras décadas del siglo XVIII. Sus personajes alegóricos y los sensibles tópicos que toca no dejan duda de tal intencionalidad. Más cuando uno de los hablantes poéticos se nos revela como una voz moralista que encarna a Lima, para la cual reclama preeminencia ante una imagen fantástica que habían creado sus principales, imagen por lo demás comprensible para una época como la del XVIII en la que el sentimiento regionalista y el amor al terruño dominaban la vida cotidiana ("Estudio preliminar" 31).

En definitiva, las grandezas de la ciudad de Santiago de Chile que anuncia el título no son tales, y los versos de la Descripción dejan claro que quedan reducidas a meras pretensiones de grandeza. Embry señala certeramente que

el análisis de contenido del poema revela un mecanismo de destrucción y minimización de las grandezas de la ciudad y, por extensión, del país. A pesar de que una visión literaria de excelencia dada se tuerce con la finalidad de mostrar un cuadro de deterioro general, el lector de hoy puede descubrir, tras la parodia de la sátira, un cuadro absolutamente inédito del interesante desarrollo económico y cultural que había alcanzado la ciudad capital del Reino de Chile en las primeras cuatro décadas del siglo XVIII ("Estudio preliminar" 11-12).

\section{CUESTIONES DE FIJACIÓN TEXTUAL Y ANOTACIÓN}

A continuación voy a ofrecer algunas notas sobre las tres ediciones modernas que existen de la Descripción. Las tres, aunque meritorias, no llegan a fijar con el deseado rigor filológico un buen texto de la obra. Añadiré después unas breves notas relativas a determinados pasajes que no han sido debidamente anotados. Con estos modestos apuntes tan solo pretendo poner de relieve, como señalaba al principio, la necesidad de una edición crítica (que considere

12 Véase también Embry, "Estudio preliminar" 45. 
y coteje todos los testimonios conservados) y rigurosamente anotada del poema.

\subsection{LA EDICIÓN DE EMBRY}

Eduardo Embry transcribe paleográficamente el manuscrito de la BNE (lo que da como resultado un texto bastante dificultoso de leer). Es más, sus criterios de edición resultan contradictorios en su mismo enunciado:

Con esta edición que el lector tiene en sus manos se trata de hacer asequible con signos actuales lo que resultaría de otro modo de penosa lectura, y a la vez se desea presentar una transcripción del manuscrito de la manera más fiel, sin transgredir nada de lo que consta en su original, habiendo hecho excepción únicamente en las pocas abreviaturas que contiene, colocando en su reemplazo la palabra completa y subrayando [destacando en cursiva] las letras que con un apóstrofe el amanuense quiso omitir ("Estudio preliminar" 12).

Pero lo que resulta más significativo es que comete numerosos y graves errores de transcripción, que a veces traen como consecuencia notas explicativas equivocadas. Examinaré a continuación una selección de esos errores y deficiencias:

Título sehores, errata por señores

v. 2 fragil femeral dolencia por frágil femenil dolencia (no hay nota para explicar ese supuesto femeral)

v. 5

Niño de quacos por niño de guacos

v. 27

sanguisami por saquisami (o sea, zaquizami), y nota equivocada al pie: "Probablemente es cultismo derivado del latín sanguis, que vale sangre"

v. 120 Banzanes, en vez de bauzanes (bausanes), y nota equivocada relacionando el término con el apellido de los Bazanes

v. 139 el Imperio por el Empíreo

v. 196 mobles, errata por nobles

v. 259 funebras, error de transcripción o errata por fúnebres

v. 414 siguelas, errata por sirgüelas

v. 465 Antonita, errata por atónita (deja la mayúscula del manuscrito e introduce una - $n$ - parásita) 
$\begin{array}{ll}\text { v. } 548 & \begin{array}{l}\text { un Alferez semi sueña, error por un alférez semidueña } \\ \text { vuego de canas, errata por juego de cañas } \\ \text { v. } 691\end{array} \\ \text { vecenas, errata por receñas (reseñas) } \\ \text { v. } 607 & \begin{array}{l}\text { puntal, errata por puntual (en la línea del ms. se lee, en } \\ \text { efecto, puntal, pero se ve claramente añadida la -u- en el } \\ \text { interlineado) }\end{array} \\ \text { v. } 620 & \begin{array}{l}\text { indulgencia, pero en el ms. indulugencia, con -u- } \\ \text { epentética }\end{array} \\ \text { v. } 645 & \begin{array}{l}\text { Pacce mihi, en vez de Parce mihi, y anotación equivocada: } \\ \text { "Tradicional cántico 'Paz para mí, en latín" }\end{array}\end{array}$

vv. 653-654 los transcribe así: "de tres soldados tan rotos / que aun desconocidos no eran", donde desconocidos es errata por descocidos, que rompe el juego de rotos / descosidos

v. 667 freiles, mala lectura por fuciles (fusiles), que trae aparejada una explicación equivocada del pasaje en el estudio preliminar

v. 706 deparan por dejaran (dexaran en el ms.)

v. 777 don Payferos, error de transcripción o errata por don Gaiferos

v. 805 con publica plaza, error de transcripción por en pública plaza

v. 819 argullo, errata por orgullo

v. 874 de Argel, error de transcripción por en Argel que deja la frase sin sentido

v. 938 Procuta en vez de Prócula (nombre de la esposa de Pilatos), que se interpreta equivocadamente como "Defensa de los derechos del pueblo, por decir "procurador"'

v. 948 deuniera por debiera (deuiera en el ms.)

vv. 949-950 finas de risa, error por finar de risa

v. 960 irresible, error de transcripción o errata por irrisible

v. 962 absequian, errata por obsequian

v. 999 entierros nochirnos por entierros nocturnos

v. 1011 infatible en vez de infalible, error de transcripción que arrastra otro en la anotación, pues explica: "Del lat. infatigabilis, infatigable" 
vv. 1055-58 los lee así: "Hablaré con solo aquellos / que por meterse en dozena, / siendo de miserias fluxo, / se introducen ã primera", y añade una nota para explicar el supuesto fluxo: "Vulgar: indisposición estomacal", sin captar el juego con el léxico de los naipes (flux / primera)

v. 1092 huelta, errata por huella

v. 1120 cuello arrimado en prenssa por cuello ahormado en prensa

v. 1196 Febas, errata por Tebas

v. 1254 infome, errata por informe

v. 1265 reponden, errata por responden

v. 1287 deshoesta, errata por deshonesta

v. 1314 toda las plaucibles, errata

v. 1383 lо тиеba, error de transcripción o errata por los muеva.

\subsection{LA EDICIÓN DE MADRIGAL}

Luis Íñigo Madrigal transcribe también el manuscrito de la BNE, eliminando los rasgos de seseo y ceceo del amanuense; pero, al modernizar, modifica expresiones que suponen cambio fonético. Por ejemplo, asumpto pasa a ser asunto, con reducción del grupo consonántico culto; impropria queda en impropia; obstenta se deja en ostenta (sin embargo, en el v. 807 se transcribe obstentación y en los vv. 946 y 966, obstenta); post pasa a pos, esentas a exentas, erutan a eructan, respectos a respetos (v. 1361), aldeguela lo transcribe aldehuela, etc.

Por otra parte, hay un uso indiscriminado de las mayúsculas y las minúsculas: curiosidad, experiencia van en minúscula, pero se trata de conceptos personificados; en cambio, muchas otras palabras quedan en mayúscula, tal como figuran en el manuscrito, sin que haya ninguna razón que lo justifique ${ }^{13}$ : Patricios (vv. 139 y 1383), Planeta (v. 152), Limbo (v. 155),

${ }^{13}$ Advierte Madrigal que "En la transcripción del poema he modernizado la ortografía y modificado la puntuación del original; mantengo con todo algunas grafías originales, tanto cultistas como populares" (162). Ni siquiera hay una uniformidad cuando una misma palabra o expresión se repite: atribuyéndola a Pepa (v. 58) pero pasan de raya tus pepas (v. 980); Abuela (vv. 65, 986, 1034 y 1114) pero abuela (v. 60); Babiecas (v. 144) pero babiecas (v. 1370); el Rey de cielos y tierra (v. 376) pero el Rey de Cielos y tierra (v. 844), etc. 
País (vv. 169, 217 y 481), Alamedas (v. 204), Mundo (v. 214), Palacios (v. 245), Pastor (v. 408), Aguardiente (v. 673), Héroes (vv. 770, 1045 y 1151), Donado (v. 1080), Potentados (v. 1094), Virgenes (v. 1313), Publicanas (v. 1314), etc.

Dos aspectos positivos presenta esta edición: señala las variantes con respecto a la sátira limeña según los poemas de Valle y Caviedes en las ediciones de Reedy y Vargas Ugarte; y hay un buen intento de anotación, adecuado para iluminar bastantes pasajes, aunque deja sin anotar algunos otros. En cualquier caso, a la hora de la fijación textual, abundan los errores de transcripción y las erratas que dejan numerosas malas lecturas en el texto. Algunos ejemplos:

v. 256 huertas en vez de puertas, error de transcripción que rompe el juego de palabras portadas / puertas

v. 292 sino es que en vez de si no es que

v. 329 un triste Isidro por un triste indio

v. 338 sin paz ni cuento en vez de sin par ni cuento, que es lo que trae claramente el ms. y hace mejor sentido

v. 415 engullándose, errata por engulléndose

v. 447 gran indignación, error de transcripción por grave indignación

v. 607 puntal ejercicio, por puntual ejercicio

vv. 867-868 lee: "Pues sin levantar perjuros, / testimonios a la letra", con una coma que separa el adjetivo del sustantivo al que califica

v. 918 duras flechas, error de transcripción por agudas flechas

v. 1019 ¿Qué, es tanta la veleidad... por ¿Que es tanta la veleidad...

v. 1118 muy estirados de ceja por muy estirados de cepa

v. 1192 espinitos por estribitos

v. 1245 la tapa cara, cuando sería mejor editar la tapacara (los anteojos)

v. 1285 los labio secos, errata. 


\title{
2.3. LA EDICIÓN DE PROMIS
}

José Promis sigue la copia manuscrita del Fondo Medina de la Biblioteca Nacional de Chile, pero indica que ha suplido con la edición de Madrigal los versos que faltan en aquella. Moderniza las grafías, incluyendo casos en que la fonética queda afectada (edita impropia en vez de impropria, prontitud en vez de promptitud, suntuosa por sumptuosa, ostenta en vez de obstenta, exentos en vez de esemptos) y ofrece una anotación somera (lo que se explica por el tipo de publicación - una amplia antología de textos con breves estudios de presentación - donde se incluye la obra). Desde el punto de vista textual, las variantes que presenta frente al manuscrito de la BNE son, en general, peores lecturas. Hay, sin embargo, algunas excepciones, es decir, algunas pocas lecturas que parecen mejores que las del manuscrito conservado en España:

v. 93 Acaba de despenarme, mejor que A causa de despenarme

v. 1190 el maná de sus despensas, mejor que es maña de sus despenzas

\subsection{Algunos Pasajes QUe ReQuieren anotación}

Dejando de lado el comentario de diversos pasajes que podrían quizá enmendarse (vv. 209-212, 308, 775, 778, 835, 842, 873, 1183-1186, 1189$1190,1324-1326 \ldots$; pero es este un aspecto en el que no puedo detenerme ahora), paso a lo relativo a la anotación. Es una cuestión muy importante en un texto como la Descripción que presenta una alta densidad de agudezas, dilogías y juegos de palabras varios. Señalo algunos ejemplos no anotados por los editores modernos (o no de forma acertada y/o suficiente), apuntando brevemente lo que habría que explicar con más detalle y con el correspondiente acarreo de pasajes paralelos:

\author{
[el celaje de Santiago] \\ puede competir con limbo \\ o apostar con la Noruega (vv. 155-156).
}

Noruega es nombre usado como sinónimo de 'oscuridad' en multitud de textos auriseculares (baste recordar, por ejemplo, el sintagma callejón Noruega del poema núm. 856 de Quevedo). 


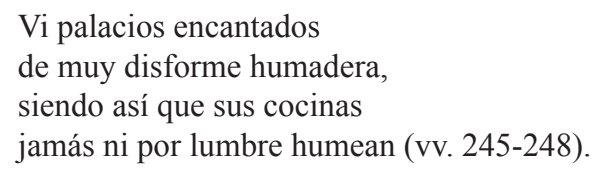

Hay un juego de palabras dilógico en ni por lumbre, que se entiende en sentido figurado ('de ninguna manera') y literal (no hay lumbre, no se hace fuego, porque no hay nada que cocinar en esos palacios de los nobles empobrecidos).

Vi una pila que, inacuosa, en una plaza desierta, a cecas y sin llover, de no correr se avergüenza (vv. 285-288).

Hay un fácil chiste dilógico en correr ('fluir' y 'avergonzarse').

[la corriente del río]

a veces parece clara

de huevo, y a veces yema (vv. 305-306).

Es chiste tópico, entre la clara corriente del agua y la clara de huevo, que trae por asociación lo de yema (chiste que a Embry se le escapa, al transcribir como yerma el yemma del manuscrito).
Vi tragarse excomuniones
como si fueran sirgüelas, engulléndose los breves como quien engulle brevas (vv. 413-416).

Habría que explicar el chiste paronomástico entre brevas ('especie de higos', en relación con sirgüelas 'jocotes, fruta parecida a la ciruela') y breves ('documentos pontificios').

Vi muchos maestros de campo, de estos de la hos campera, muy graduados de servicios de ollería o de secreta (vv. 569-572).

Por un lado, se juega con maestros de campo ('generales') y hos campera (hoz es imagen grotesca para referirse a la 'espada'); además, el sentido de 
servicios / de ollería ('orinales'), que guarda relación con secreta ('letrina'), es otro muy diferente al de servicios ('los prestados en la milicia') que se pueden alegar como méritos. Encontramos un juego similar en este otro pasaje:

Vieja ¿Esos son aquellos grandes servicios de viva guerra que en sus vanas pretenciones por meritorios alegan?

Perico ¿Servicios, decís, señora? Hay servicios que pudieran servir en los hospitales para las heses superfluas (vv. 609-616).

Embry transcribe paleográficamente esses, lo que dificulta la comprensión del chiste servicios / heces, y no anota nada.

¡Oh, qué claro es el chiquillo

en medio de su simpleza!

¡A fe que, para escribano,

es el muchacho una perla! (vv. 863-866).

Hay juego dilógico en claro, aludiendo a la letra clara que necesariamente han de tener los escribanos.

¿No haces conmemoración

de las femíneas bellezas

que ya, por hijas del aire,

jusgo Semíramis bellas? (vv. 1199-1202)

Estas damas son "hijas del aire" porque su hermosura es cosa vana, aparente; y precisamente por ser hijas del aire pueden parangonarse con Semíramis, la heroína protagonista de la tragedia calderoniana, en dos partes, titulada La hija del aire.

No me toques a ese punto, señora, porque me peza que así carguéis la romana a matronas tan honestas (vv. 1207-1210). 
Hay un doble juego dilógico entre pesar ('causar pena' y 'calcular un peso') y romana ('un tipo de báscula' y 'mujer natural de Roma', sentido este último que se activa por la mención de matronas).

\author{
... aquellas que, descaradas, \\ dando en cara su insolencia, \\ se tapan de ojo, por ver \\ si da de ojos la torpeza; \\ aquellas cosarias que, \\ para abordar faltriqueras, \\ se ponen la tapacara; \\ en fin, mulitas chilenas (vv. 1239-1246).
}

Las damas a las que alude el pasaje son "mulitas chilenas" porque, del mismo modo que las mulas llevan anteojeras (tapacara), ellas se tapan de medio ojo y se convierten así en cosarias (corsarias, piratas) que pueden sacar sus dineros (abordar faltriqueras) a los incautos. Es decir, se trata del conocido tópico satírico de la dama pidona.

En fin, hay en la Descripción muchos otros pasajes y/o expresiones que requerirían de la correspondiente anotación explicativa: la alusión a las calesas esqueletos (vv. 257-260); la dilogía de echando chispas (v. 563), jugando con el significado literal y la frase hecha; el chiste dilógico basado en compañia ('de soldados' y 'lo contrario de soledad'), así como la referencia a los plumajes de los soldados (vv. 578-584); las alusiones a los caballeros chirles (v. 773) y todo lo relacionado con la falsa nobleza (vv. 779-794); la mención de las tarascas (v. 822), que se explica perfectamente en el contexto del Corpus al que alude el pasaje; Ginebra (v. 850), que connota 'protestantismo'; los pavones reales, hermosos pero con unas patas muy feas de las que se avergüenzan (vv. 1071-1174); la creencia de que los camaleones se alimentan del aire (vv. 1151-1154); la alusión a unos "fantasmas galanes, / don Guindos de la comedia" (vv. 1167-1168); el juego dilógico de ducados 'monedas' y 'dominios de los duques' (vv. 1179-1182), etc.

\title{
BIBLIOGRAFÍA
}

Descripción de las grandezas de la ciudad de Santiago de Chile dedicadas [sic] por el desengaño a los muy Illustres Señores gamonales de ella: escrita este año de 1740. Transcripción, anotaciones lingüísticas e historiográficas y análisis de contenido por Eduardo Embry. Roma: Bulzoni Editore, 1994. 
Descripción de las grandezas de la ciudad de Santiago de Chile, dedicadas [sic] por el Desengaño a los muy ilustres señores gamonales de ella, año de 1740. En José Promis, La literatura del Reino de Chile. Valparaíso: Editorial de la Universidad de Playa Ancha, 2002. 529-547.

Descripción de las grandezas de la Ciudad de Santiago de Chile dedicadas [sic] por el desengaño a los muy ilustres señores Gamonales de ella: escrita este año de 1740, en Luis Íñigo Madrigal. "Descripción de las grandezas de Santiago de Chile (un poema del XVIII, deudor de Caviedes). Estudio, transcripción y notas". Anales de Literatura Hispanoamericana (Madrid, Editorial Complutense) 23 (1994): 163-195.

Descripción de las grandezas de la ciudad de Santiago de Chile, dedicada por el desengaño a los muy Illustres señores Gamonales de ella: escrita este año de 1740, en Varios de Lima, ms. 17.667 de la Biblioteca Nacional de España, fols. 152r-175v.

Descripción de las grandezas de la ciudad de Santiago de Chile..., ms. del Fondo Medina de la Biblioteca Nacional de Chile.

Embry, Eduardo. "Una descripción disidente de Santiago de Chile del siglo XVIII". Anales (Gotemburgo) 3-4 (1991-1992): 67-108.

"Estudio preliminar". Descripción de las grandezas de la ciudad de Santiago de Chile dedicadas por el desengaño a los muy Illustres Señores gamonales de ella: escrita este año de 1740. Roma: Bulzoni Editore, 1994. 9-45.

"Santiago de Chile al revés según una sátira del XVIII". Actas del XXIX Congreso del Instituto Internacional de Literatura Iberoamericana. (Barcelona, 15-19 de junio de 1992). Tomo II, volumen 1. Ed. J. Marco. Barcelona: PPU, 1994. 31-48.

Lasarte, Pedro. Mateo Rosas de Oquendo, "Sátiras a las cosas que pasan en el Pirú, año de 1598”: estudio y edición. Tesis Doctoral. Ann Arbor, University of Michigan Press, 1983.

“La Vieja y el Periquillo: una aproximación a la Lima de Juan del Valle y Caviedes". Caliope IV/1-2 (1998): 125-139.

Lima satirizada (1598-1698): Mateo Rosas de Oquendo y Juan del Valle y Caviedes. Lima: Pontificia Universidad Católica del Perú, 2006.

Lohmann Villena, Guillermo. "Gamonal: del nombre propio al nombre común”. Boletín de la Academia Peruana de la Lengua 35 (2002): 25-46.

Lorente Medina, Antonio. "La transmisión textual de la poesía de Valle y Caviedes". El Siglo de Oro en el nuevo milenio. Actas del Congreso Internacional (Pamplona, Universidad de Navarra, septiembre de 2003). Tomo II. Ed. Carlos Mata y Miguel Zugasti. Pamplona: Eunsa, 2005. 1069-1087.

Madrigal, Luis Íñigo. "Descripción de las grandezas de Santiago de Chile (un poema del XVIII, deudor de Caviedes). Estudio, transcripción y notas". Anales de Literatura Hispanoamericana (Madrid, Editorial Complutense) 23 (1994): 153-219.

Mata Induráin, Carlos. 'El soneto de Cervantes 'A la entrada del Duque de Medina en Cádiz'. Análisis y anotación filológica”. Cervantes y Andalucia: biografia, escritura, recepción. Ed. Pedro Ruiz Pérez. Estepa: Ayuntamiento de Estepa, 1999. 143-163.

Medina, José Toribio. Historia de la literatura colonial de Chile. Santiago de Chile: Imprenta de la Librería de El Mercurio, 1878, 3 vols. 
Paz, Julián. Catálogo de los manuscritos de América existentes en la Biblioteca Nacional. 2. ${ }^{\text {a }}$ ed. revisada y aumentada por Clotilde Olaran y Mercedes Jalón. Madrid: Biblioteca Nacional de España, 1992.

Promis, José. La literatura del Reino de Chile. Valparaíso: Editorial de la Universidad de Playa Ancha, 2002.

Roca, Pedro. Catálogo de manuscritos que pertenecieron a D. Pascual de Gayangos existentes hoy en la Biblioteca Nacional. Madrid: Tipografía de la Revista de Archivos, Bibliotecas y Museos, 1904.

Valle y Caviedes, José del. Obra completa. Ed., prólogo, notas y cronología de Daniel R. Reedy. Caracas: Biblioteca Ayacucho, 1984.

Obra completa. Ed. M. ${ }^{a}$ Leticia Cáceres, Luis Jaime Cisneros y Guillermo Lohmann Villena. Lima: Banco de Crédito del Perú, 1990.

Obra poética, II, Poesías sueltas y bailes. Ed., introducción y notas de Luis García-Abrines Calvo, con la colaboración de Sydney Jaime Muirden. Jaén: Diputación Provincial de Jaén, 1994.

Obras. Ed. Rubén Vargas Ugarte. Lima: Tipografía Peruana, 1947. 